\title{
Autophagy mediates oral submucous fibrosis
}

\author{
JIANG LI ${ }^{1}$, TING-TING ZHAO ${ }^{1}$, PENG ZHANG ${ }^{2}$, CHAO-JIN XU $^{2}$, \\ ZHUO-XIANG RONG $^{3}$, ZI-YI YAN ${ }^{1}$ and CHANG-YUN FANG ${ }^{1}$
}

\author{
${ }^{1}$ Oral Medical Center, Xiangya Hospital, Central South University, Changsha, Hunan 410000; ${ }^{2}$ Department of \\ Histology and Embryology, Institute of Neuroscience, Wenzhou Medical University, Wenzhou, Zhejiang 325035; \\ ${ }^{3}$ Center for Molecular Medicine, Xiangya Hospital, Central South University, Changsha, Hunan 410000, P.R. China
}

Received March 20, 2015; Accepted January 15, 2016

DOI: $10.3892 / \mathrm{etm} .2016 .3145$

\begin{abstract}
Oral submucous fibrosis (OSF) is a chronic insidious disease of the oral mucosa, well-recognized as a premalignant condition and commonly found in Southern China. It is primarily caused by the habit of areca nut or gutkha chewing. OSF is believed to be a homeostatic disorder of the extracellular matrix and fibroblast proliferation. The present study demonstrated a novel link between autophagy and OSF. Tissue samples from human OSF showed an overexpression of the autophagy marker microtubule-associated protein 1 light chain 3 using immunohistochemistry and quantitative polymerase chain reaction. With regard to the crucial role of transforming growth factor (TGF)- $\beta$ in OSF disease, western blot analysis demonstrated that TGF- $\beta$ signaling was shown to contribute to the activation of autophagy in fibroblasts in vitro; however, a cell apoptosis and MTS assay demonstrated that the suppression of autophagy ameliorated the fibrosis induced by active TGF- $\beta$ receptor type I signaling, as well as promoted fibroblast apoptosis and suppressed proliferation. Therefore, the present results suggest that autophagy serves a crucial function in OSF.
\end{abstract}

\section{Introduction}

Oral submucous fibrosis (OSF) has been described as an insidious chronic disease, affecting any part of the oral cavity and in certain cases the pharynx (1). The incidence rate of oral squamous cell carcinoma in patients with OSF, after a follow-up period of 17 years, has been estimated to be $7.6 \%$ (2). Areca-associated oral squamous cell carcinoma is the third most common malignancy in the developing world (3). Despite the fact that OSF is, at times, preceded by and/or linked to vesicle formation, it is known to be associated with

Correspondence to: Professor Chang-Yun Fang, Oral Medical Center, Xiangya Hospital, Xiangya Street, Central South University, 87 Xiangya Road, Changsha, Hunan 410000, P.R. China E-mail: 978707328@qq.com

Key words: oral submucous fibrosis, microtubule-associated protein light chain 3 , autophagy, transforming growth factor- $\beta$ a juxta-epithelial inflammatory reaction, which is followed by a fibroelastic change of the lamina propria, with epithelial atrophy resulting in stiffness of the oral mucosa and causing inability to eat and trismus (4).

Autophagy is a lysosomal degradation pathway that turns superfluous or damaged cell components into basic biomolecules, which are then recycled back into the cytosol (5). Autophagy has been categorized into the following three catabolic processes: Microautophagy, macroautophagy and chaperone-mediated autophagy, which are responsible for the degradation of cell components in the lysosome $(6,7)$. This morphological process was originally described 50 years ago (8). A study focusing on determining the pathogenesis of organic fibrosis emphasized the possibility that the condition may be linked with autophagy, which triggers tissue fibrogenesis (9). Markers of oxidative stress have also been identified in patients with OSF $(1,10)$, and another study has suggested that elevated reactive oxygen species or oxidative stress may activate autophagic reaction (11). Autophagy has also been shown to be sensitive to oxygen tension, and hypoxia-inducible factor (HIF)- $1 \alpha$ has been implicated as a major regulator of autophagy under hypoxic conditions (12). Patients with OSF have been found to exhibit elevated levels of HIF-1 $\alpha$ (1), which may contribute to the progression of the disease, suggesting that autophagy is likely to be induced in OSF.

In the present study, human tissues and an in vitro transforming growth factor (TGF)- $\beta$ model were used to investigate the association of autophagy with OSF. The results demonstrated that autophagy may mediate the TGF- $\beta$-induced OSF.

\section{Materials and methods}

Patients. A total of 10 male volunteers were included in the study (age, 20-45 years). Five OSF buccal mucosa specimens from areca quid chewers and 5 healthy specimens from non-areca quid chewers were provided by the Department of Pathology of Xiangya Hospital, Central South University (Changsha, China). The diagnosis was based on the histological examination of the sections following staining with hematoxylin and eosin. Written informed consent from all patients and approval from the Institutional Research Ethics Committee were obtained for the use of these clinical materials in the present study. 
Reverse transcription quantitative polymerase chain reaction $(R T-q P C R)$. Total RNA from cell cultures was isolated using TRIzol reagent (Invitrogen; Thermo Fisher Scientific, Inc.) according to the manufacturer's protocol. mRNA $(1 \mu \mathrm{g})$ was reverse-transcribed using a PrimarScript RT Regent kit (Takara Biotechnology Co., Ltd., Dalian, China). RNA was isolated and reverse transcribed into cDNA. RT-qPCR was performed using Applied Biosystems 7500 Real-Time PCR System (Applied Biosystems, Thermo Fisher Scientific, Inc., Foster City, CA, USA) by mixing equal quantities of cDNA, iQ SYBR Green Supermix (Bio-Rad Laboratories Inc., Hercules, CA, USA) and specific primers. PCR thermal cycling conditions were as follows: $95^{\circ} \mathrm{C}$ For $30 \mathrm{sec}$, followed by 40 cycles of $95^{\circ} \mathrm{C}$ for $5 \mathrm{sec}, 60^{\circ} \mathrm{C}$ for $30 \mathrm{sec}, 95^{\circ} \mathrm{C}$ for $15 \mathrm{sec}, 60^{\circ} \mathrm{C}$ for $15 \mathrm{sec}$ and $95^{\circ} \mathrm{C}$ for $15 \mathrm{sec}$. All quantitative data were normalized against $\beta$-actin. The primers used in RT-qPCR screening were as follows: Collagen type 1 alpha 2 (Col1A2) forward, 5'-AAG GTCATGCTGGTCTTGCT-3' and reverse, 5'-GACCCTGTT CACCTTTTCCA-3'; and microtubule-associated protein 1 light chain 3 (LC3) forward, 5'-GAGTGGAAGATGTCCGGC TC-3' and reverse, 5'-CCAGGAGGAAGAAGGCTTGG-3'. The were analyzed using the $2^{-\triangle \Delta C q}$ method (13), and presented as fold increases relative to GAPDH.

Immunohistochemistry. Paraffin-embedded samples were obtained from 5 healthy volunteers with non-areca quid chewers for immunohistochemical analysis. Paraffin-embedded sections $(4 \mu \mathrm{m})$ were deparaffinized and rehydrated. Endogenous peroxidase activity was blocked using $3 \% \mathrm{H}_{2} \mathrm{O}_{2}$ for $15 \mathrm{~min}$ at $95^{\circ} \mathrm{C}$. Following antigen retrieval, the sections were incubated with $5 \%$ serum (Gibco; Thermo Fisher Scientific, Inc.) to avoid non-specific binding. The sections were incubated overnight at $4^{\circ} \mathrm{C}$ with an anti-LC3 rabbit polyclonal primary antibody at a dilution of 1:100 (cat. no. 3868; Cell Signaling Technology, Inc., Danvers, MA, USA). Following washing of the primary antibody, the sections were incubated with a peroxidase-conjugated AffiniPure goat anti-rabbit antibody (1:500; cat. no. sc-45101; Santa Cruz Biotechnology, Inc., Santa Cruz, CA, USA) for $90 \mathrm{~min}$ at room temperature. Immunoreactivity was visualized using 3',3-diaminobenzidine reaction, then hematoxylin was used to counter-stain the sections (both purchased from ZSGB-BIO, Beijing., China). For the blank control, the primary antibody was omitted. For the negative control, the primary antibody was replaced with non-immune serum. The stained slides were scored independently by two pathologists blinded to the clinical data. Staining was graded semi-quantitatively as follows: 0 , Absent expression or nuclear expression only; $1+$, cytoplasmic faint, barely perceptible staining not exceeding background in any percentage of cells; $2+$, cytoplasmic staining exceeding background in 0 to $50 \%$ of tumor cells; and $3+$, cytoplasmic staining exceeding background in $>50 \%$ tumor cells.

Cell culture. Human fibroblasts were prepared as outgrowth cultures from 5 healthy oral mucosa biopsies, and were subsequently cultured as previously described (14). In selected experiments, fibroblasts were stimulated with recombinant TGF- $\beta$ (10 ng/ml; R\&D Systems, Ambington, UK) and 5, 10 and $15 \mu \mathrm{M}$ chloroquine (CQ; C6628; Sigma-Aldrich, St. Louis,
MO, USA), an autophagy inhibitor. Stimulation experiments were performed in Dulbecco's modified Eagle's medium/10\% phosphate-buffered saline (PBS) (both purchased from Gibco; Thermo Fisher Scientific, Inc.). Fibroblasts from passages 4-8 were used for the experiments.

Western blot analysis. Protein was extracted from the fibroblast in radio-immunoprecipitation assay buffer $(50 \mathrm{mM}$ Tris-hydrochloride, pH 8, $150 \mathrm{mM} \mathrm{NaCl}, 0.1 \%$ SDS, $1 \%$ NP-40, $0.5 \%$ sodium deoxycholate, $0.57 \mathrm{mM}$ phenylmethanesulfonyl fluoride and $1 \mu \mathrm{g} / \mathrm{ml}$ aprotinin), consisting of the

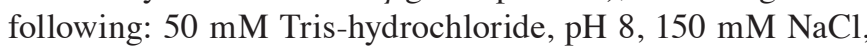
$0.1 \%$ SDS, $1 \%$ NP-40, $0.5 \%$ sodium deoxycholate, $0.57 \mathrm{mM}$ phenylmethanesulfonyl fluoride and $1 \mu \mathrm{g} / \mathrm{ml}$ aprotinin. Protein samples $(30 \mu \mathrm{g})$ were separated using $12 \%$ sodium dodecyl sulfate polyacrylamide gel electrophoresis gels (Bio-Rad Laboratories, Inc.) and transferred to polyvinylidene difluoride membranes (EMD Millipore, Billerica, MA). The membranes were blocked with $5 \%$ non-fat milk in Tris-buffered saline (Sigma-Aldrich) with $1 \%$ Tween-20 for $1 \mathrm{~h}$ at room temperature, and immunoblotted with an anti-LC rabbit polyclonal antibody (1:1,000; Cell Signaling Technology, Inc.) and an anti-tubulin mouse monoclonal antibody (cat. no. sc-69969; Santa Cruz Biotechnology, Inc.) at $4^{\circ} \mathrm{C}$ for $1 \mathrm{~h}$. The binding of the primary antibodies was detected following incubation with goat anti-rabbit or anti-mouse horseradish peroxidase-conjugated secondary antibodies (cat. no. sc-395758; Santa Cruz Biotechnology, Inc.) at room temperature, and was visualized using ECL Western Blotting Detection Reagents (Amersham Pharmacia Biotech (UK) Ltd., Little Chalfont, UK) following exposure to chemiluminescent film (Bio-Rad Laboratories, Inc.). Densiometry analysis was performed using an ImageJ Gel Analysis tool (National Institutes of Health, Bethesda, MA, USA).

MTS assay. Measurements were made according to the manufacturer's protocol. Briefly, $20 \mu \mathrm{l}$ MTS reagent (Promega Corporation, Madison, WI, USA) was added directly to the wells of the 96-well plates, and cells were incubated at $37^{\circ} \mathrm{C}$ for a minimum of $2 \mathrm{~h}$. Absorbance was measured using a SpectraMax Plus 384 reader (Molecular Devices; Sunnyvale, CA, USA) at $490 \mathrm{~nm}$. Initially, background absorbance was subtracted using a set of wells that only contained medium. It was then normalized against and expressed as a relative percentage of the plate-averaged dimethyl sulfoxide (Amresco, Inc., Farmingham, MA, USA) control.

Cell apoptosis assay. Cell apoptosis was analyzed using flow cytometry (FCM) (Guava easyCyte; EMD Millipore). The apoptotic cells were differentiated from the viable or necrotic ones by combined application of annexin V-fluorescein isothiocyanate (FITC) and propidium iodide (PI). The samples were washed twice and adjusted to a concentration of $1 \times 10^{6}$ cells $/ \mathrm{ml}$ with cold PBS. Subsequently, $10 \mu 1$ annexin V-FITC and $10 \mu \mathrm{l}$ PI (both purchased from BD Biosciences, Franklin Lakes, NJ, USA) were added into $100 \mu$ l cell suspension, and incubated for $15 \mathrm{~min}$ at room temperature in the dark. Finally, $400 \mu \mathrm{l}$ binding buffer was added to each sample without washing, and analyzed using FCM. Each experiment was performed at least in triplicate. 
A
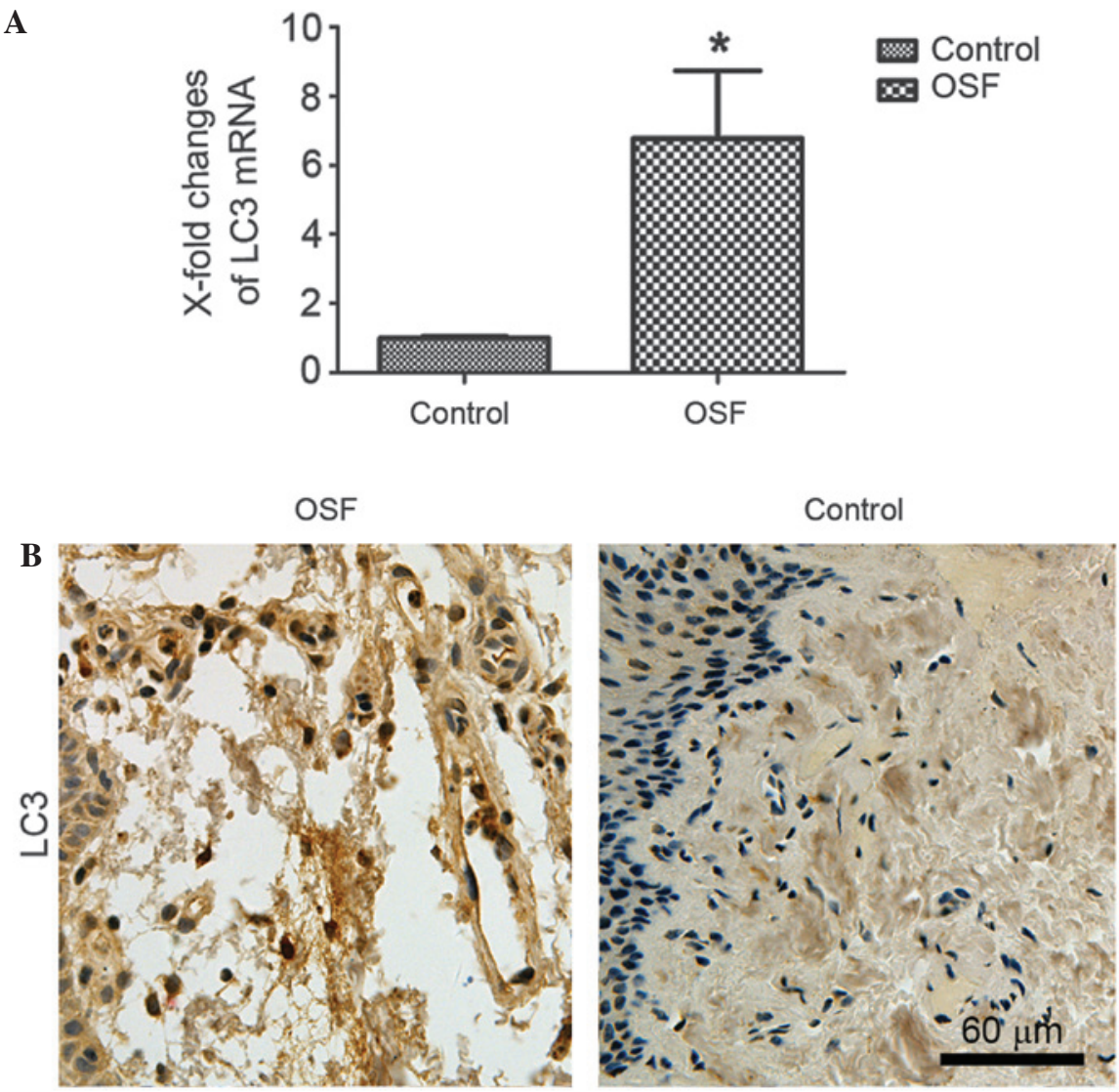

Figure 1. (A) The mRNA levels of the autophagy gene LC3 were significantly increased in patients with OSF compared with those in the control (n=5 per group). (B) LC3 was overexpressed in specimens from 5 patients with OSF; 5 samples of non-fibrotic oral submucous are shown (magnification, $\mathrm{x} 400$ ). All data are expressed as the mean \pm standard error. ${ }^{*} \mathrm{P}<0.05$ vs. healthy volunteers (analyzed using the Mann-Whitney U-test). OSF, oral submucous fibrosis; LC3, microtubule-associated protein 1 light chain 3.
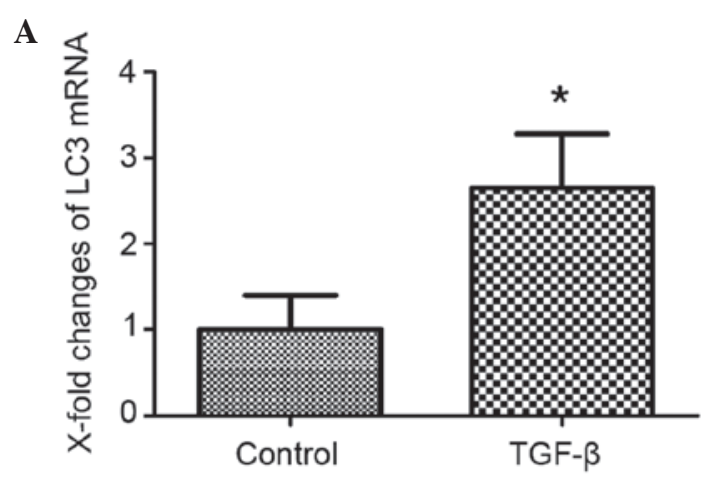

B

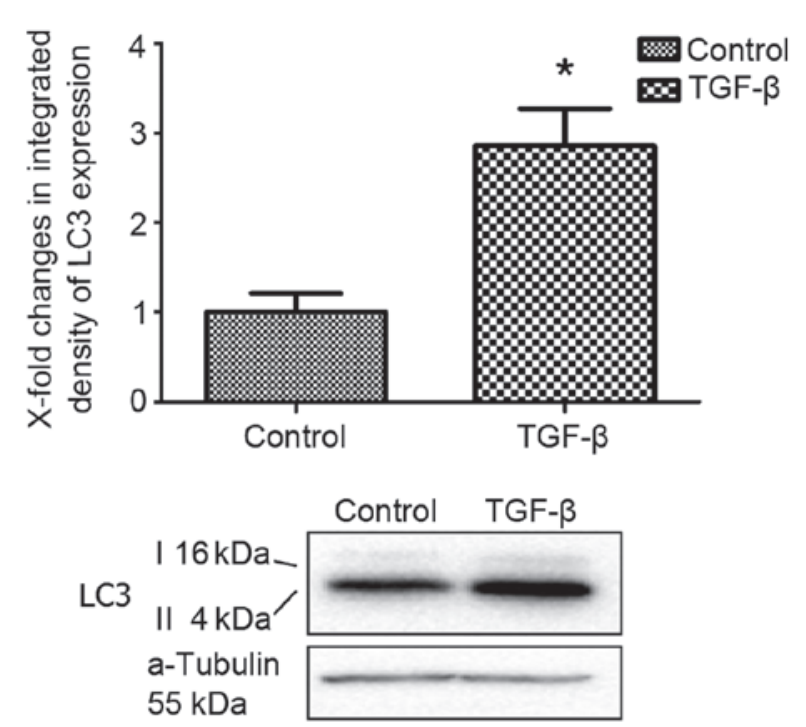

Figure 2. (A) Human oral fibroblasts were cultured and treated with TGF- $\beta$. (B) TGF- $\beta$ induced the overexpression of LC 3 mRNA and promoted the activation of LC3, increasing the intensity of the lower band on the western blot. " $\mathrm{P}<0.05$ vs. control. TGF- $\beta$, transforming growth factor- $\beta$; LC3, microtubule-associated protein 1 light chain 3 .

Statistical analysis. Data are expressed as the mean \pm standard error. The Wilcoxon signed-rank test was used for related samples, and the Mann-Whitney U test was used for non-related samples. In subsets of experiments, the mean value of the control groups was set to 1 . All other values were expressed as $\mathrm{x}$-fold changes, compared with the respective controls used as 'comparison mean values'. $\mathrm{P}<0.05$ was considered to indicate a statistically significant difference. 


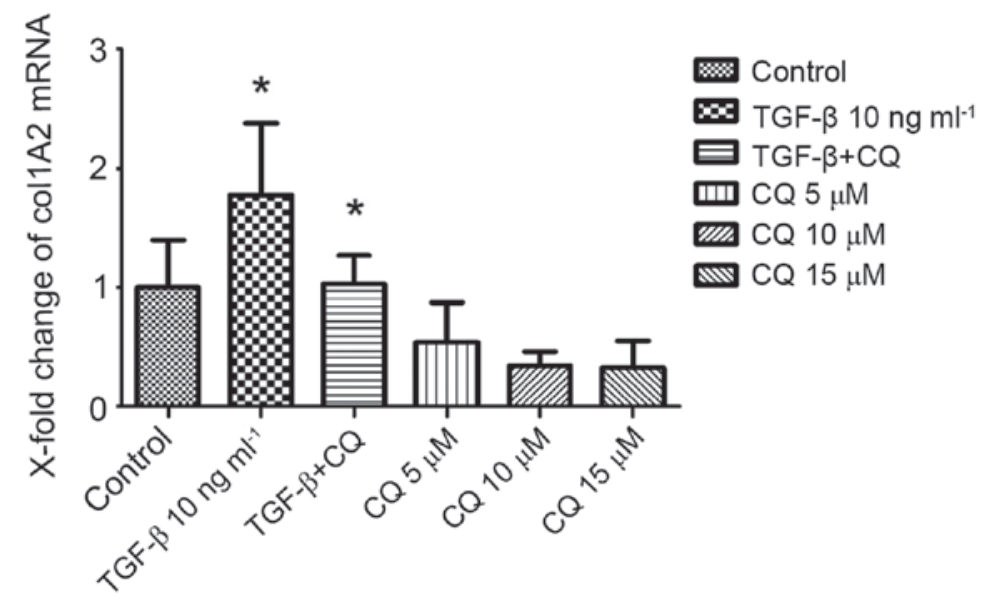

Figure 3. Incubation with CQ decreased the mRNA levels of collagen type 1 alpha 2 and counteract the effect of TGF- $\beta$ on the fibroblast ( $\mathrm{n}=3$ ). ${ }^{*} \mathrm{P}<0.05$ vs. control. CQ, chloroquine; TGF- $\beta$, transforming growth factor $-\beta$.

A
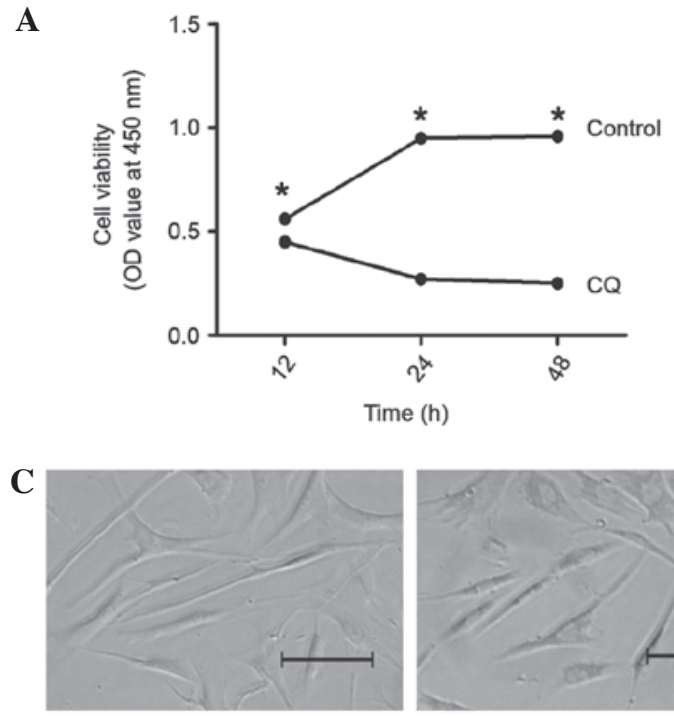

Control

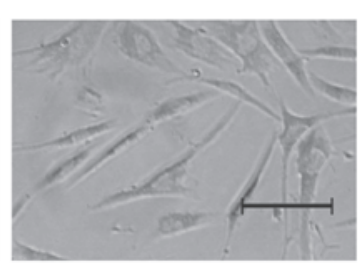

$\mathrm{CQ}(10 \mu \mathrm{M})$
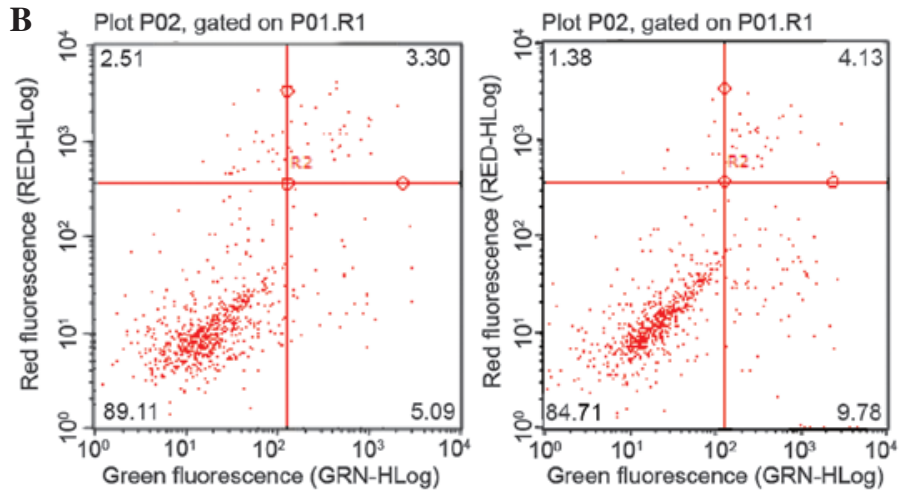

Control
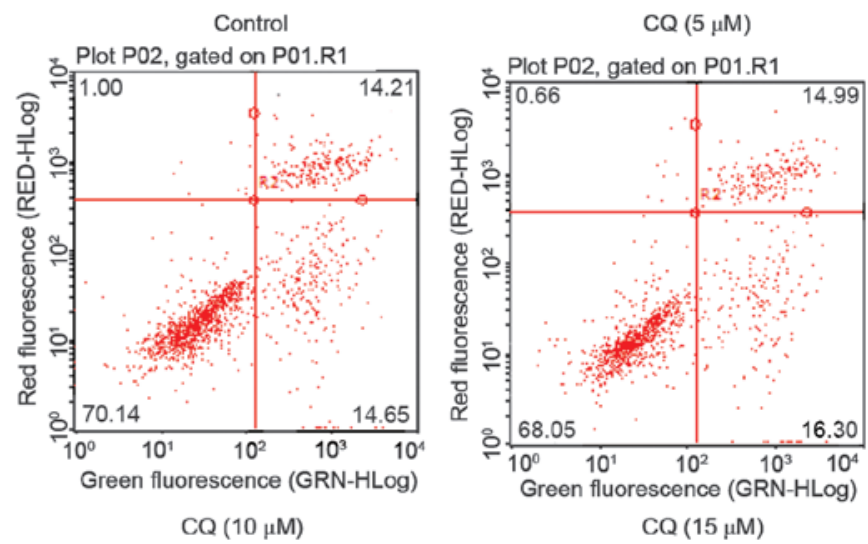

Figure 4. (A) MTs analysis of cell viability following incubation with CQ $(5 \mu \mathrm{M})$ or control plasmid. (B) Flow cytometric analysis of cell apoptosis following incubation with different concentrations of CQ, or with control plasmid. (C) CQ induced bubble formation. All experiments were repeated at least in triplicate. Scale bar, $200 \mu \mathrm{m}$. *P<0.05 vs. control. CQ, chloroquine; OD, optical density.

\section{Results}

Overexpression of autophagy in OSF. In order to determine the role of the autophagy in OSF, the expression profiling of LC3 in OSF, which was commonly used to monitor autophagy in cultured cells and organization tissue, was investigated. As shown in Fig. 1A, LC3 was significantly upregulated in OSF samples compared with normal oral mucosa tissues. Overall, the paraffin-embedded OSF samples showed positive expression of LC3. The representative immunostaining of LC3 in
OSF samples was shown in Fig. 1B. All the results show that autophagy is activated in OSF.

TGF- $\beta$ activates autophagy in fibroblasts. Due to the crucial role of TGF- $\beta$ in fibrotic disease, we speculated that TGF- $\beta$ signaling might contribute to the activation of autophagy. To investigate the effect of TGF- $\beta$ on autophagic activity, the turnover of LC3 in lysosomes was directly evaluated (15). Stimulation with TGF- $\beta$ in cultured fibroblasts induced the overexpression of LC3 mRNA (Fig. 2A). In addition, the LC3-II 
protein levels were found to be significantly higher than those in the control group.

LC3, also known as MAP1LC3, is commonly used to monitor autophagy in cultured cells and animal tissues (16). The cytosolic form of LC3 (termed LC3-I) is represented by the upper band of the immunoblot, and the autophagosomal membrane lipidated form of LC3 (termed LC3-II) is represented by the lower band (17). In combination, these data indicated that TGF- $\beta$ induced autophagy in cultured fibroblasts.

Inhibition of autophagy decreased critical fibrogenic gene (CollA2) expression in fibroblasts. To investigate the functional role of the autophagy in OSF, human oral fibroblasts were incubated with CQ, the only inhibitor of autophagy available for use in clinical practice (18). CQ suppresses the transcriptional activity in Col1A2 reporter assays. Consistently, a dose-dependent reduction in collagen release was observed in the supernatants of fibroblasts stimulated with CQ. Notably, the stimulatory effects of CQ were comparable to those of TGF- $\beta$, which is considered to be a potent profibrotic mediator (Fig. 3).

Suppressing autophagy promotes apoptosis in fibroblasts while suppressing proliferation. Fibroblasts were incubated with CQ and subjected to MTS assay. A significant reduction was observed in the growth rate of $5 \mu \mathrm{m}$ CQ-incubated cells, as compared with those incubated with the control (Fig. 4A). In order to determine the mechanism of growth inhibition in CQ-incubated fibroblasts, the apoptotic rate of the cells was analyzed. FCM showed that CQ increased the apoptotic rate, as compared with the control group (Fig 4B). In addition, the inhibition of autophagy was shown to disrupt the physiological tissue architecture (Fig. 4C). These data suggested that CQ inhibited the growth of fibroblasts by inducing cell apoptosis via the suppression of autophagy.

\section{Discussion}

Activation of the autophagy appears to be a general feature of OSF, well-described elevations in endoplasmic reticulum stress $(19,20)$, oxidative stress (21), and HIF-1 $\alpha$ (22), all of which are known to induce autophagy. Indeed, pathologically activated autophagy has been associated with various fibrotic diseases (23-27). An overexpression of the autophagy marker LC3 was observed in human samples from a number of patients with OSF. These changes resulted in the activation of the autophagy pathway and increased transcription of target genes in OSF.

Autophagy is crucially involved in collagen release in OSF (28). In the present study, CQ inhibits the release of collagen in fibroblasts, indicating that the inhibition of autophagy may be effective in acute and chronic fibrotic diseases. The activation of the autophagy pathway and its potent profibrotic effects suggest that autophagy may be a potential target for novel antifibrotic approaches. In the present study the autophagy inhibitor CQ was selected for the inhibition of the autophagy pathway for the following reasons: Firstly, it is able to diffuse across cell membranes, undergo protonation and accumulate in acidic organelles, such as lysosomes (29); secondly, it is a 4-aminoquinoline drug used in the treatment of numerous diseases; and thirdly, this approach allows broader inhibition of autophagy compared with targeting single autophagy proteins (30).

Activated TGF- $\beta$ signaling is considered to be a common characteristic of fibrotic diseases (31). The present results highlighted the crosstalk between TGF- $\beta$ signaling and autophagy, while suggesting that TGF- $\beta$ activates autophagy. Stimulation with TGF- $\beta$ in cultured fibroblasts induced the overexpression of LC3; a TGF- $\beta$-mediated increase of LC3 was identified as a potential molecular mechanism. Furthermore, autophagy inhibition by CQ significantly reduced the stimulatory effects of TGF- $\beta$ on fibroblasts. These findings suggested that the interaction between autophagy and TGF- $\beta$ is a crucial mechanism in fibrotic diseases. TGF- $\beta$ has been shown to trigger the activation of numerous intracellular signaling cascades (32); however, the molecular mediators of the profibrotic effects of TGF- $\beta$ are not yet fully understood, and the optimal targets for antifibrotic treatments have not yet been identified. Although the central role of TGF- $\beta$ signaling in the fibrotic process has been confirmed (33), the first attempts of targeting TGF- $\beta$ signaling in humans failed (34). CAT-192, a neutralizing antibody against TGF- $\beta 1$, was inefficient in this regard due to the low-affinity binding of TGF- $\beta 1$ (34). Furthermore, an attempt to target the downstream mediator c-Abl, in combination with platelet-derived growth factor receptor, did not prove particularly successful (35). The inhibition of the autophagy pathway may provide a novel approach for the prevention of the profibrotic effects of TGF- $\beta$ signalling.

It was observed in the present study that suppressing autophagy promoted apoptosis in fibroblasts while suppressing proliferation, demonstrated that autophagy promoted fibroblast proliferation and anti-apoptosis. In fibrogenic cells, the lipophagy of lipid droplets (LDs) by autophagy provides cellular energy critical to fuel the catabolic pathways of cellular activation. The inhibition of autophagy leads to an increase in triglyceride-containing LDs, which is associated with a reduction in the total adenosine triphosphate levels and may be partially reversed by the addition of the free fatty acid oleate (9). The crucial role of autophagy in cell survival was demonstrated in previous studies using Atg-knockout mice. Mice deficient in Atg3, Atg5, Atg7, Atg9 or Atg16L1 failed to induce autophagy and died on the day of birth, due to the starvation that followed the disruption of the trans-placental nutrient supply (36). Furthermore, mice with neuron-specific Atg5 or Atg7 knockout suffer from neurodegeneration and apoptotic neuronal death, and T-cell-specific Atg5 deficiency leads to an increase in the peripheral T-cell apoptosis upon T-cell activation (37-39). In addition, it has been reported that autophagy is not induced in idiopathic pulmonary fibrosis, despite the upregulation of several activators of autophagy (40).

In conclusion, autophagy is a complex process and the exact mechanism remains to be elucidated. It was demonstrated in the present study that the inhibition of autophagy can decrease the expression of Col1A 2 and protect from TGF- $\beta$-induced fibrosis, indicating one mechanism by which autophagy may mediate fibrogenesis.

\section{Acknowledgements}

This study was supported by the Hunan Provincial Natural Science Foundation of China (grant no. 2015JJ4074). 


\section{References}

1. Tilakaratne WM, Iqbal Z, Teh MT, Ariyawardana A, Pitiyage G, Cruchley A, Stewart JE, Hagi-Pavli E, Lalli A, Waseem A, et al: Upregulation of HIF-1alpha in malignant transformation of oral submucous fibrosis. J Oral Pathol Med 37: 372-377, 2008.

2. Rajalalitha P and Vali S: Molecular pathogenesis of oral submucous fibrosis - a collagen metabolic disorder. J Oral Pathol Med 34: 321-328, 2005.

3. Shieh TM, Tu HF, Ku TH, Chang SS, Chang KW and Liu CJ: Association between lysyl oxidase polymorphisms and oral submucous fibrosis in older male areca chewers. J Oral Pathol Med 38: 109-113, 2009.

4. Pindborg JJ and Sirsat SM: Oral submucous fibrosis. Oral Surg Oral Med Oral Pathol 22: 764-779, 1966.

5. Wirawan E Vanden Berghe T, Lippens S, Agostinis P and Vandenabeele P: Autophagy: For better or for worse. Cell Res 22: 43-61, 2012.

6. Mizushima N, Levine B, Cuervo AM and Klionsky DJ: Autophagy fights disease through cellular self-digestion. Nature 451: 1069-1075, 2008

7. Boya P and Codogno P: Micronucleophagy: A new mechanism to protect against chromosomal instability? Cell Cycle 11: 645-646, 2012.

8. Ashford TP and Porter KR: Cytoplasmic components in hepatic cell lysosomes. J Cell Biol 12: 198-202, 1962.

9. Hernández-Gea V and Friedman SL: Autophagy fuels tissue fibrogenesis. Autophagy 8: 849-850, 2012.

10. Wang CC, Liu TY, Wey SP, Wang FI and Jan TR: Areca nut extract suppresses T-cell activation and interferon-gamma production via the induction of oxidative stress. Food Chem Toxicol 45: 1410-1418, 2007.

11. Kiffin R, Bandyopadhyay U and Cuervo AM: Oxidative stress and autophagy. Antioxid Redox Signal 8: 152-162, 2006.

12. Zhang H, Bosch-Marce M, Shimoda LA, Tan YS, Baek JH, Wesley JB, Gonzalez FJ and Semenza GL: Mitochondrial autophagy is an HIF-1-dependent adaptive metabolic response to hypoxia. J Biol Chem 283: 10892-10903, 2008.

13. Livak KJ and Schmittgen TD: Analysis of relative gene expression data using real-time quantitative PCR and the $2^{-\Delta \Delta \mathrm{Ct}}$ method. Methods 25: 402-408, 2001

14. Akhmetshina A, Dees C, Pileckyte M, Szucs G, Spriewald BM, Zwerina J, Distler O, Schett G and Distler JH: Rho-associated kinases are crucial for myofibroblast differentiation and production of extracellular matrix in scleroderma fibroblasts. Arthritis Rheum 58: 2553-2564, 2008.

15. Mizushima N, Yoshimori T and Levine B: Methods in mammalian autophagy research. Cell 140: 313-326, 2010.

16. Lee E, Koo Y, Ng A, Wei Y, Luby-Phelps K, Juraszek A, Xavier RJ, Cleaver O, Levine B and Amatruda JF: Autophagy is essential for cardiac morphogenesis during vertebrate development. Autophagy 10: 572-587, 2014.

17. Mizushima N, Yamamoto A, Matsui M, Yoshimori T and Ohsumi Y: In vivo analysis of autophagy in response to nutrient starvation using transgenic mice expressing a fluorescent autophagosome marker. Mol Biol Cell 15: 1101-1111, 2004

18. Maycotte P, Aryal S, Cummings CT, Thorburn J, Morgan MJ and Thorburn A: Chloroquine sensitizes breast cancer cells to chemotherapy independent of autophagy. Autophagy 8: 200-212, 2012.

19. Korfei M, Ruppert C, Mahavadi P, Henneke I, Markart P, Koch M, Lang G, Fink L, Bohle RM, Seeger W, et al: Epithelial endoplasmic reticulum stress and apoptosis in sporadic idiopathic pulmonary fibrosis. Am J Respir Crit Care Med 178: 838-846, 2008.

20. Lawson WE, Cheng D, Degryse AL, Tanjore H, Polosukhin VV, $\mathrm{Xu} \mathrm{XC}$, Newcombe DC, Jones BR, Roldan J, Lane KB, et al: Endoplasmic reticulum stress enhances fibrotic remodeling in the lungs. Proc Natl Acad Sci USA 108: 10562-10567, 2011.

21. Kliment CR and Oury TD: Oxidative stress, extracellular matrix targets, and idiopathic pulmonary fibrosis. Free Radic Biol Med 49: 707-717, 2010.
22. Tzouvelekis A, Harokopos V, Paparountas T, Oikonomou N, Chatziioannou A, Vilaras G, Tsiambas E, Karameris A, Bouros D and Aidinis V: Comparative expression profiling in pulmonary fibrosis suggests a role of hypoxia-inducible factor-1alpha in disease pathogenesis. Am J Respir Crit Care Med 176: 1108-1119, 2007.

23. He Y, Jin L, Wang J, Yan Z, Chen T and Zhao Y: Mechanisms of fibrosis in acute liver failure. Liver Int 35: 1877-1885, 2015.

24. De Stefano D, Villella VR, Esposito S, Tosco A, Sepe A, De Gregorio F, Salvadori L, Grassia R, Leone CA, De Rosa G, Maiuri MC et al: Restoration of CFTR function in patients with cystic fibrosis carrying the F508del-CFTR mutation. Autophagy 10: 2053-2074, 2014.

25. He L, Livingston MJ and Dong Z: Autophagy in acute kidney injury and repair. Nephron Clin Pract 127: 56-60, 2014.

26. Gomez-Arroyo J, Sakagami M, Syed AA, Farkas L, Van Tassell B, Kraskauskas D, Mizuno S, Abbate A, Bogaard HJ, Byron PR and Voelkel NF: Iloprost reverses established fibrosis in experimental right ventricular failure. Eur Respir J 45: 449-462, 2015.

27. Lee JH, Jang EJ, Seo HL, Ku SK, Lee JR, Shin SS, Park SD, Kim SC and Kim YW: Sauchinone attenuates liver fibrosis and hepatic stellate cell activation through TGF- $\beta /$ Smad signaling pathway. Chem Biol Interact 224C: 58-67, 2014.

28. Junkins RD, McCormick C and Lin TJ: The emerging potential of autophagy-based therapies in the treatment of cystic fibrosis lung infections. Autophagy 10: 538-547, 2014.

29. Solomon VR and Lee H: Chloroquine and its analogs: A new promise of an old drug for effective and safe cancer therapies. Eur J Pharmacol 625: 220-233, 2009.

30. Morgan MJ, Gamez G, Menke C, Hernandez A, Thorburn J, Gidan F, Staskiewicz L, Morgan S, Cummings C, Maycotte P and Thorburn A: Regulation of autophagy and chloroquine sensitivity by oncogenic RAS in vitro is context-dependent. Autophagy 10: 1814-1826, 2014.

31. Verrecchia F and Mauviel A: Transforming growth factor-beta and fibrosis. World J Gastroenterol 13: 3056-3062, 2007.

32. Shi Y and Massagué J: Mechanisms of TGF-beta signaling from cell membrane to the nucleus. Cell 113: 685-700, 2003.

33. Akhmetshina A, Palumbo K, Dees C, Bergmann C, Venalis P, Zerr P, Horn A, Kireva T, Beyer C, Zwerina J, et al: Activation of canonical Wnt signalling is required for TGF- $\beta$-mediated fibrosis. Nat Commun 3: 735, 2012.

34. Denton CP, Merkel PA, Furst DE, Khanna D, Emery P, Hsu VM, Silliman N, Streisand J, Powell J, Akesson A, et al; Cat-192 Study Group; Scleroderma Clinical Trials Consortium: Recombinant human anti-transforming growth factor beta 1 antibody therapy in systemic sclerosis: A multicenter, randomized, placebo-controlled phase I/II trial of CAT-192. Arthritis Rheum 56: 323-333, 2007.

35. Gordon J, Mersten J, Lyman S, Kloiber SA, Wildman HF, Crow MK, Kirou KA and Spiera RF: Imatinib mesylate (Gleevec) in the treatment of systemic sclerosis: Interim results of a phase IIa, one year, open label clinical trial. In: American College of Rheumatology (ACR)/Association of Rheumatology Health Professionals (ARHP) Scientific Meeting 2009. Pennsylvania, 2009.

36. Kuma A and Mizushima N: Physiological role of autophagy as an intracellular recycling system: With an emphasis on nutrient metabolism. Semin Cell Dev Biol 21: 683-690, 2010.

37. Komatsu M, Waguri S, Chiba T, Murata S, Iwata J, Tanida I, Ueno T, Koike M, Uchiyama Y, Kominami E and Tanaka K: Loss of autophagy in the central nervous system causes neurodegeneration in mice. Nature 441: 880-884, 2006.

38. Hara T, Nakamura K, Matsui M, Yamamoto A, Nakahara Y, Suzuki-Migishima R, Yokoyama M, Mishima K, Saito I, Okano H and Mizushima N: Suppression of basal autophagy in neural cells causes neurodegenerative disease in mice. Nature 441: 885-889, 2006.

39. Pua HH, Dzhagalov I, Chuck M, Mizushima Nand He Y: A critical role for the autophagy gene Atg 5 in T cell survival and proliferation. J Exp Med 204: 25-31, 2007.

40. Patel AS, Lin L, Geyer A, Haspel JA, An CH, Cao J, Rosas IO and Morse D: Autophagy in idiopathic pulmonary fibrosis. PLoS One 7: e41394, 2012. 